\title{
ENFRENTANDO O RACISMO NAS AULAS DE SOCIOLOGIA
}

\section{FACING RACISM IN SOCIOLOGY CLASSESS}

\author{
Isabela Rodrigues Ligeiro \\ Universidade do Estado de Minas Gerais - UEMG \\ José Eustáquio de Brito \\ Universidade do Estado de Minas Gerais - UEMG
}

\section{RESUMO}

Esse artigo apresenta resultados de uma pesquisa de mestrado em educação, realizada entre 2018 e 2019, que objetivou compreender como aulas e atividades propostas por professores de sociologia do ensino médio têm contribuído para o desenvolvimento de uma educação das relações étnico-raciais tendo por intenção a implementação a Lei 10639/o3. Os sujeitos da pesquisa são professores de sociologia em atividade na capital mineira e Região Metropolitana de Belo Horizonte. Fez-se uma revisão bibliográfica sobre a temática em que se destaca o debate sobre a relação histórica da sociologia com as questões raciais no Brasil e o processo de conquista e implementação da Lei 10639/o3. Pesquisa qualitativa, com dados obtidos a partir da aplicação de questionário e entrevistas, que revelaram diversas possibilidades para um ensino de sociologia comprometido com a abordagem crítica das relações étnico-raciais. Possibilitaram também a compreensão de como essas práticas têm contribuído para o campo da educação das relações étnico-raciais e os desafios a serem enfrentados para uma efetiva educação antirracista.

Palavras-chave: Ensino de Sociologia. Práticas Pedagógicas. Racismo.

\section{ABSTRACT}

This article presents the results of a master's research in education, carrie out between 2018 and 2019. The research aimed to understand how classes and activities proposed by high school sociology teachers have contributed to the development of an education in ethnic-recial relations with intention of implementation of Law 10639/03. The research subjets are sociology teachers working in the capital of Minas Gerais and the Metropolitan Region of Belo Horizonte city. A bibliographic review was made on the theme highlighted the historical relationshisp of sociology with racial issues in Brazil and the process of implementation of Law 10639/o3. The qualitative research data were obtained from the application of a questionnaire and interviews wich revealed approach to ethnic-racial relations. They also made it possible to undestand how 
these practices have contributed to the education of ethnic-racial relations and the challenges to be faced for an effective anti-racist education.

Keywords: Teaching of Sociology; Pedagogical Practices; Racism. 


\section{INTRODUÇÃO}

Nesse artigo são apresentados resultados de pesquisa desenvolvida no Programa de Mestrado em Educação, da Universidade do Estado de Minas Gerais, entre os anos de 2018 e 2019, que objetivou compreender como práticas pedagógicas de professores de sociologia do ensino médio estão contribuindo para uma educação das relações étnicoraciais, uma vez que o racismo configura-se um traço estrutural em nossa sociedade. Intentou-se investigar como práticas docentes abordam a temática no sentido de implementar as orientações da Lei 10639/o3, como têm enfrentado o racismo e debatido o tema sob a perspectiva do ensino de sociologia.

De acordo com Nilma Lino Gomes (2012), a Lei 10639/o3 é uma conquista do Movimento Negro de nosso país, que luta cotidianamente para mudar a realidade enfrentada pelo povo negro em nossa sociedade. Para Gomes (2012) descolonizar os currículos é um desafio para a escola, que deve ser encampado uma vez que um currículo que não dialoga com a realidade social vivida pelos jovens, que não se propõe a enfrentar as violências produzidas pelo racismo, que não forma professores e professoras reflexivos, que não compreende que é necessário escutar a história que até agora foi invisibilizada e negada, não estará descolonizando os saberes. Para a autora, a Lei 10639/o3 se propõe a construir uma educação antirracista, e afirma:

\footnotetext{
Nesse sentido, mais do que a efetivação política de uma antiga reivindicação do Movimento Negro para a educação, a Lei $\mathrm{n}^{0}$ 10.639/03, o parecer CNE/CP 03/2004 e a resolução CNE/CP 01/2004 e os desdobramentos deles advindos nos processos de formação de professores/as, na pesquisa acadêmica, na produção de material didático, na literatura, entre outros, deverão ser considerados como mais um passo no processo de descolonização do currículo. (GOMES, 2012, p. 107)
}

No contexto escolar, atitudes discriminatórias ocorrem entre os próprios estudantes, ou são manifestadas por professores e equipes pedagógicas, bem como estão implícitas em currículos e práticas que perpetuam referências à inclusão precária do negro em nossa sociedade. Essas práticas não são exclusivas do espaço escolar indicando tratarse de um conjunto de manifestações que reproduzem desigualdades existentes na sociedade. Entretanto, sendo a escola uma instituição de formação e lugar onde possíveis 
transformações podem intervir nessa realidade, sustenta-se que uma educação que busque uma formação humana tem o compromisso ético de assumir a luta antirracista como um valor a orientar práticas pedagógicas, assim como a sociologia, enquanto uma disciplina que visa à compreensão da realidade social, tem um papel fulcral nessa construção.

Num primeiro momento, partindo de uma revisão bibliográfica, a realização da pesquisa consistiu na aplicação de um questionário destinado a professores de sociologia de Belo Horizonte e Região metropolitana, a fim de traçar um perfil desses docentes acerca das práticas pedagógicas de enfrentamento ao racismo e a lei 10639/03. A partir das respostas, foram selecionados os professores para as entrevistas. O questionário foi enviado para aproximadamente 300 (cento e cinquenta) professores e obteve-se o retorno de 24 (vinte e quatro) questionários. A partir da análise das respostas ao questionário, optou-se por entrevistar 7 (sete) professores de sociologia que responderam que implementavam as orientações para uma educação das relações étnico-raciais e que tinham conhecimento sobre a lei 10639/03. As entrevistas foram conduzidas com base na técnica de entrevista semiestruturada

Além dessa introdução e das considerações finais, o artigo encontra-se organizado em 3 (três) partes. Na primeira, apresentamos uma reflexão sobre o processo histórico de colonização e colonialidade em sua relação com o racismo e as políticas de ações afirmativas. Em seguida, abordamos a questão da institucionalização da sociologia em nosso país, o seu ensino e a questão racial. Bem como a descrição e análise de práticas docentes que têm contribuído para o enfrentamento do racismo finalizam as reflexões propostas no artigo.

\section{COLONIALIDADE, RACISMO E AÇÕES AFIRMATIVAS}

Para Nelson Maldonado Torres (2007) o colonialismo é conceituado como uma relação política e econômica em que um povo se constitui supostamente como superior e apto a ser soberano, submetendo outros povos. Embora a colonização entendida como relação de submissão direta da colônia pela metrópole seja uma experiência histórica 
datada, ela não encerra a colonialidade, que representa, para além de uma relação de poder entre duas nações ou povos, a imposição de um modo de viver, pensar e agir.

Estudos decoloniais apontam a colonização e consequente colonialidade da sociedade como processo constitutivo da relação imposta de superioridade de um povo sobre outros povos. No caso do Brasil da suposta superioridade branca em relação à pretensa inferioridade da população negra e indígena. $\mathrm{O}$ conceito de colonialidade do poder, de Aníbal Quijano (2009), aponta como as relações de colonialidade estabelecem uma classificação da humanidade, gerando diferentes modos de opressão, como a desigualdade entre as raças. A colonialidade gera, portanto, modos de viver e pensar o mundo, produzindo uma historiografia baseada na superioridade da Europa, impõe valores e ideias sustentados na hierarquização das raças. Em “Colonialidade do poder, eurocentrismo e América Latina”, Quijano (2005) discorre sobre o processo de organização da modernidade e como esse processo incidiu na construção de uma perspectiva de conhecimento que demonstra o padrão mundial do poder: colonial/moderno, capitalista e eurocentrado. Esse padrão de poder cria, de acordo com esse autor, o eurocentrismo, que é

o nome de uma perspectiva de conhecimento cuja elaboração sistemática começou na Europa Ocidental antes de meados do século XVII, ainda que algumas de suas raízes são sem dúvida mais velhas, ou mesmo antigas, e que nos séculos seguintes se tornou mundialmente hegemônica percorrendo o mesmo fluxo do domínio da Europa burguesa. Sua constituição ocorreu associada à específica secularização burguesa do pensamento europeu e à experiência e às necessidades do padrão mundial de poder capitalista, colonial/moderno, eurocentrado, estabelecido a partir da América. (QUIJANO, 2005, p. 126)

O eurocentrismo elabora conhecimentos acadêmicos e orienta os currículos escolares sustentados na cultura e história europeia, do colonizador, invisibilizando e subalternizando a história e cultura dos povos colonizados. Maíra Pires Andrade (2018) pontua que é fundamental compreender o currículo brasileiro a partir dessa concepção, que para ela "torna legítimo para o ensino somente a cultura do colonizador, que é branca, masculina, heterossexual e cristã, trazendo à tona no espaço escolar as discriminações, 
exclusões e o racismo" (ANDRADE, 2018, p. 243). A autora reforça como esses mecanismos de poder, expressos na colonialidade, permanecem nos espaços escolares ainda hoje.

Entretanto, os sujeitos que têm suas histórias negadas e subalternizadas, que estão nas fronteiras - físicas e imaginárias - da modernidade, não eram e não são seres passivos, pois resistem e constroem suas próprias narrativas e conhecimentos. No contexto brasileiro, Petronilha Beatriz Gonçalves e Silva (1997) afirma que as primeiras iniciativas dos negros brasileiros para discutir questões referentes à pluralidade étnica do país datam do final dos anos quarenta, do século XX. A partir de suas experiências, a população negra discute a necessidade de pautar a história do seu povo. Gomes (2010) aponta a importância da presença dos negros e negras na pesquisa científica e produção do conhecimento, pois a partir do lugar de sujeitos (e não mais objetos) da pesquisa reconfiguram a produção do conhecimento. É com essa perspectiva que os movimentos negros e intelectuais negros inserem a defesa da educação em suas pautas, mobilizam a população e impulsionam políticas públicas.

Cavalheiro (2005) discorre a respeito das consequências de uma educação colonizada e eurocentrada, em que a ausência no cotidiano escolar, no currículo, nos materiais, nas práticas pedagógicas, da cultura e história afro-brasileira e africana, resulta em um ambiente hostil e limitador de aprendizagem para os (as) alunos(as) negros(as), acarretando muitas vezes a exclusão deles(as) da escola ou em defasagem de aprendizado. Em sentido semelhante a autora nos traz uma reflexão de Kabengele Munanga:

o preconceito incutido na cabeça do professor e sua incapacidade em lidar profissionalmente com a diversidade, somando-se ao conteúdo preconceituoso dos livros e materiais didáticos e às relações preconceituosas entre os alunos de diferentes ascendências étnico-raciais, sociais e outras, desestimulam o aluno negro e prejudicam seu aprendizado (MUNANGA apud CAVALLEIRO, 2005, p.70).

As consequências do racismo no cotidiano escolar para a vida das crianças e jovens são perversas, podendo acarretar aos negros o sentimento de auto-rejeição, com 
dificuldade de se sentirem pertencentes à identidade negra; baixa autoestima, uma vez que seus padrões estéticos quase nunca são reconhecidos, bem como sua capacidade pessoal não é valorizada; desprezo e ofensa aos outros negros, com uma reprodução constante do racismo recreativo (MOREIRA, 2019); pouca ou nenhuma participação em sala de aula; dificuldades no processo de aprendizagem; desgosto com a escola e colegas; dificuldade de relacionamentos interpessoais; e consequentemente, evasão escolar.

Contudo compreender como o racismo se manifesta no cotidiano da educação e reconhecer sua existência é uma condição para se pensar uma educação antirracista, que promova relações interpessoais respeitáveis e igualitárias no cotidiano da escola. Sobretudo para os grupos sociais excluídos, entre eles os negros e negras, a instituição escolar pode ser capaz de contribuir como agente de processos pedagógicos mais transformadores.

Nesse sentido, as políticas de ação afirmativas tão necessárias em contextos onde se fazem presentes os efeitos da colonialidade, se impõem como um imperativo político em busca da reversão de um quadro de desigualdades raciais. Tais políticas buscam, dentre outras possibilidades, afirmar o acesso à educação para a população negra em todos os níveis, o direito à diversidade étnico-racial combatendo o silenciamento sobre a realidade africana e afro-brasileira. Gomes destaca que ações afirmativas

são políticas, projetos e práticas públicas e privadas que visam à superação de desigualdades que atingem historicamente determinados grupos sociais, a saber: negros, mulheres, homossexuais, indígenas, pessoas com deficiência, entre outros. Tais ações são passíveis de avaliação e têm caráter emergencial, sobretudo no momento em que entram em vigor. Elas podem ser realizadas por meio de cotas, projetos, leis, planos de ação, etc. (GOMES, 2011, p.1).

As pressões do movimento negro pela adoção de ações afirmativas e cumprimento pelo governo dos acordos assinados na Terceira Conferência Mundial contra o Racismo, a Discriminação Racial, a Xenofobia e Formas Correlatas de Intolerância, promovida pela Organização das Nações Unidas em 2001, na cidade de Durban, África do Sul, se 
desdobram em ações concretas em nosso país, principalmente em políticas públicas voltadas para a educação.

A partir de 2003, com a eleição do presidente Luiz Inácio Lula da Silva, do Partido dos Trabalhadores (PT), o Estado brasileiro redefine seu papel na luta por uma sociedade disposta a enfrentar o racismo mediante formulação e adoção de políticas públicas, reconhecendo as desigualdades raciais, e passa a intervir de forma mais efetiva no combate a essas desigualdades. Em janeiro de 2003, na implementação das pautas de Durban e no atendimento a reivindicações do movimento negro, Lula sanciona a Lei 10.639, alterando a Lei 9394/96 - Lei de Diretrizes e Bases da Educação Nacional. Essa lei é considerada uma ação afirmativa de ampla relevância para a luta antirracista no nosso país. Em março daquele mesmo ano, é criada a Secretaria Especial de Políticas de Promoção da Igualdade Racial (Seppir), e em 2004, no Ministério da Educação, é constituída a Secretaria de Educação Continuada, Alfabetização e Diversidade (Secad).

A Lei 10.639 altera LDB de 1996 em seus artigos 26-A e 79-B, instituindo a obrigatoriedade do ensino da história e cultura da África e dos afro-brasileiros no currículo escolar do ensino fundamental e médio de todas as instituições de ensino básico do país. Além disso, inclui no calendário escolar o dia 20 de novembro como "Dia Nacional da Consciência Negra”. Para Gomes (2012) a Lei 10639/03 abre perspectivas para a realização de uma mudança estrutural na construção de uma educação antirracista, e afirma,

Nesse sentido, mais do que a efetivação política de uma antiga reivindicação do Movimento Negro para a educação, a Lei $\mathrm{n}^{0}$ 10.639/o3, o parecer CNE/CP 03/2004 e a resolução $\mathrm{CNE} / \mathrm{CP}$ 01/2004 e os desdobramentos deles advindos nos processos de formação de professores/as, na pesquisa acadêmica, na produção de material didático, na literatura, entre outros, deverão ser considerados como mais um passo no processo de descolonização do currículo. (GOMES, 2012, pg. 107)

Com isso reconhecemos a relevância de termos tido, pela primeira vez, em 2002, a presença de uma intelectual e ativista do movimento negro na composição do Conselho Nacional de Educação, a professora Dra. Petronilha Beatriz Gonçalves e Silva, que foi responsável pela elaboração do Parecer CNE/CP 3/2004, que regulamenta as Diretrizes 
Curriculares Nacionais para a Educação das Relações Étnico-Raciais e para o Ensino de História e Cultura Afro-brasileira e Africana instituído pela Resolução CNE/CP 1/2004.

Além disso, ocorreram diversas ações que buscaram fortalecer a implantação e implementação da Lei 10639/o3 nos anos subsequentes à sua aprovação. Gomes cita algumas dessas estratégias que considera terem sido importantes para implementação dessa Lei:

Foram publicados 29 títulos da Coleção Educação para Todos (Secad/ UNESCO), dos quais seis se referem à implementação da Lei 10.639/ 2003. O Programa Diversidade ainda desenvolveu, entre 2005 e 2008, a linha editorial Educação e Diversidade Étnico-racial. Foram publicados ou tiveram a publicação apoiada 23 títulos, somando uma tiragem de 1.223 .900 exemplares. Destaca-se, ainda, a publicação das Diretrizes Curriculares Nacionais para a Educação das Relações Étnico-Raciais e para o Ensino de História e Cultura Afro-brasileira e Africana distribuída para as 215 mil escolas ativas no Brasil, segundo o Censo Escolar do INEP/MEC. (GOMES, 2009, p. 53)

Sendo assim, o enfrentamento ao racismo e a efetivação da lei 10639/o3 perpassam a construção de práticas pedagógicas que contemplem os processos identitários do povo negro, conferindo visibilidade à história dos afro-brasileiros e africanos de modo a romper com a postura da discriminação racial

Nesse sentido, entende-se o papel dos professores de sociologia enquanto agentes de transformação social que vislumbram uma educação que supere práticas consubstanciadas no saber hegemônico e excludente, ao acompanhar, orientar e debater o trabalho junto aos docentes e estudantes.

\section{SOCIOLOGIA BRASILEIRA, ENSINO DE SOCIOLOGIA E A QUESTÃO RACIAL.}

Na busca pela compreensão da realidade social, a sociologia já sofreu inúmeros ataques, seja enquanto ciência, seja enquanto disciplina no ensino médio. Ao propor uma análise crítica da sociedade e suas desigualdades, as humanidades contribuem para o 
combate ao conservadorismo, às ideias reacionárias e às posturas que desconsideram a diversidade e pluralidade de perspectivas.

Ao analisarmos a construção histórica dessa disciplina e da própria sociologia brasileira, identificamos que elas já serviram para reprodução ou manutenção da ideia dominante na sociedade, dos pensamentos que serviam ao poder dominante, de uma teoria e uma prática nem sempre orientadas por uma abordagem crítica. Seja desenvolvendo literaturas e pesquisas conservadoras ou progressistas é fato que a sociologia teve papel fundamental na construção da cultura brasileira e suas identidades nacionais. É evidente também que a identidade nacional construída do Brasil está intrinsicamente ligada à questão racial. Guimarães assinala que,

Desde a Independência, temos um projeto de nação que está ligado à construção de um Estado nacional; deixamos de ser parte do Estado português, passamos a formar um Estado brasileiro mantendo a escravidão, mas tínhamos já integrado um número grande de pretos libertos, de homens livres de cor, e a importância da cor não cessou de crescer desde então. (GUIMARÃES, 2003, p. 100)

Ao longo do século XIX, a escravidão foi a grande questão do Brasil, tratada por alguns como uma instituição arcaica que comprometia o desenvolvimento econômico e social (porque os negros atrasavam o país). Com o fim do sistema escravista os negros e seus descendentes passam a ser o problema, pois era representados como uma raça inferior. Essa ideia é desenvolvida pelo racismo científico no século XIX em que cientistas, principalmente antropólogos e sociólogos, a partir de métodos da biologia e da medicina, classificaram os seres humanos por meio do conceito de raça. (SCHWARCZ, 1993).

Na primeira metade do século XX, há um movimento de construção da identidade nacional forjado a partir da miscigenação, que passa a ser trabalhada como algo "positivo". A partir dos estudos de Gilberto Freyre, estabeleceu-se a ideologia da democracia racial brasileira como referência explicativa da formação do povo brasileiro, dando a entender que a miscigenação resultou de uma relação harmônica entre os grupos raciais aqui existentes. Em Casa-Grande \& Senzala, Freyre (1954), aponta a mistura brasileira como 
algo pacífico, em que a colonização portuguesa foi suave e tolerante, e por isso ocorreu a mestiçagem racial. Sobre esse mito diz Moura:

O mito do bom senhor de Freyre é uma tentativa sistemática e deliberadamente bem montada e inteligentemente arquitetada para interpretar as contradições estruturais do escravismo como simples episódio epidérmico, sem importância, e que não chegaram a desmentir a existência dessa harmonia entre exploradores e explorados durante aquele período. (MOURA, 1986, p.18)

Essa concepção da mistura das raças no Brasil e consequente democracia racial foi introjetada na consciência da população, de modo a considerar que por esse motivo não existe racismo no Brasil. No entanto, as relações sociais na vida real se passam de modo diferente; as pessoas negras, mesmo que de ascendência miscigenada, não são tratadas da mesma forma que os brancos. Pelo contrário, como afirma Ronaldo Sales no artigo "Democracia racial: o não-dito racista",

A miscigenação não eliminou a discriminação, apenas a pluralizou, matizou, modalizou, conforme a presença ou a ausência gradual de características "negras", mas principalmente pela tonalidade da cor da pele - de um racismo bivalente para um racismo polivalente (ou mesmo ambivalente) (SALES, 2006, p. 233).

Em estudos posteriores, sociólogos brasileiros passaram a questionar a ideologia da democracia racial e buscaram revelar o racismo existente na constituição da nação brasileira. Em 1954 ocorre a formação da chamada "Escola de Sociologia Paulista” ou "Escola da USP", sob a direção de Florestan Fernandes, que, dentre outros temas, desenvolveu pesquisas acerca das relações raciais no Brasil. De acordo com Guimarães (2003), Florestan Fernandes, Roger Bastide e Costa Pinto rompem radicalmente com a ideia da democracia racial e a colocam no patamar de mito, estabelecendo uma discussão que aponta a existência do preconceito racial no Brasil.

Entretanto, a imagem que perdura nas mentes de grande parte da população é a da democracia racial, legitimando ações preconceituosas e discriminatórias, demostrando como a sociologia e suas teorias são poderosas na produção e reprodução de elementos culturais, bem como na explicação dos mesmos. Em 1986, Clovis Moura já criticava a 
postura das ciências sociais e apontava para a necessidade de se fazer uma sociologia que abordasse os problemas étnicos no Brasil a partir do negro, e afirmava que

Os estudos sobre o negro brasileiro, nos seus diversos aspectos, têm sido mediados por preconceitos acadêmicos, de um lado, comprometidos com uma pretensa imparcialidade científica, e, de outro, por uma ideologia racista racionalizada, que representa os resíduos da superestrutura escravista, e, ao mesmo tempo, sua continuação, na dinâmica ideológica da sociedade competitiva que a sucedeu. Queremos dizer, com isto, que houve uma reformulação dos mitos raciais reflexos do escravismo, no contexto da sociedade de capitalismo dependente que a sucedeu, reformulação que alimentou as classes dominantes do combustível ideológico capaz de justificar o peneiramento econômico-social, racial e cultural a que ele está submetido atualmente no Brasil através de uma série de mecanismos discriminadores que se sucedem na biografia de cada negro (MOURA, 1986, p. 17).

Jessé Souza (2017) considera que a construção da identidade nacional brasileira foi forjada pelos estudos dos nossos sociólogos, desde Freyre, a Sérgio Buarque de Holanda, Roberto da Matta, até Florestan Fernandes e outros. De acordo com o autor, as análises da realidade do Brasil feitas por esses intelectuais serviram para construir uma produção da versão dominante da nossa identidade. Para ele, a aparência crítica de muitas pesquisas na verdade não passava de pesquisas que não iam na raiz do problema brasileiro, que para ele é a escravidão, e por isso mesmo eram críticas só na aparência. A sociologia brasileira foi responsável, portanto, por consolidar alguns estereótipos referentes à população brasileira e particularmente à população negra, mas também por questionar a construção histórica das relações raciais em nosso país.

\subsection{A INSTITUCIONALIZAÇÃO DO ENSINO DE SOCIOLOGIA NO BRASIL}

Em termos históricos, a Sociologia no Brasil surge anteriormente nas escolas e depois nas universidades. Na prática, a sociologia foi incluída como disciplina no Colégio Pedro II no ano de 1925. Em seguida começou a ser introduzida nos cursos preparatórios e cursos superiores. A partir desse período intelectuais começaram a produzir materiais e pesquisas que contribuíram para fortalecer o surgimento das primeiras turmas de sociologia na universidade, sendo em 1934 a primeira turma de sociologia na 
Universidade de São Paulo, tendo como norte a pesquisa sobre miscigenação racial, momento em que se fortalece a perspectiva da democracia racial orientada a partir do estudo de Gilberto Freyre, "Casa Grande e Senzala” (FILHO, 2015).

Posteriormente a essa primeira aparição a sociologia esteve presente e ausente por várias vezes, porém nunca definitivamente, cunhando sua marca de intermitência nas escolas e com poucas opções para ser uma matéria consolidada na educação básica. Diversas foram as tentativas para garantir a presença dessa disciplina nas escolas secundárias. Entretanto, a partir de 1964, com a instauração da ditadura militar, identifica-se a maior resistência em permitir o ensino dessa disciplina para os jovens na educação básica, por ser considerada uma disciplina subversiva. Na busca de substituir o papel da sociologia nas escolas, em 1971, com a nova Lei de Diretrizes e Bases da Educação (LBD) - Lei 5692, foram criadas as disciplinas Educação Moral e Cívica, Organização Social e Política do Brasil. Essas disciplinas objetivavam disseminar a ideologia do governo militar a partir da educação básica, formando a opinião dos jovens em relação a suas realidades de maneira acrítica, em oposição ao que a sociologia propunha ${ }^{1}$.

Em 1996, com a nova LDB, temos um passo para a efetivação da sociologia, ainda sem garantia efetiva enquanto disciplina, mas enquanto conteúdo que ganhava adesão na sociedade. Em 2008 a Lei 11.684 altera a LDB inserindo a sociologia enquanto disciplina com a obrigatoriedade de ser implementada a partir de 2009 em todas as instituições de educação básica, no Ensino Médio. A partir desse momento que se intensifica a produção sobre a sociologia no ensino médio, sobre seus objetivos, seu currículo, seu papel. Esse processo ainda está em andamento.

A partir dos anos 2000, principalmente com a obrigatoriedade da sociologia no ensino médio, algumas pesquisas foram produzidas com o intuito de debater e encontrar saídas para os desafios apresentados acima. "O estado da arte da produção científica sobre o ensino de sociologia na educação básica”, de Handfas e Maçaira (2014), desenvolveu um

\footnotetext{
${ }^{1}$ De acordo com Thiago, Filho \& Martorano (1982), a extensão da Educação Moral e Cívica ao nível superior recebeu a denominação de "Estudos de Problemas Brasileiros". Essa medida foi consubstanciada mediante publicação do Decreto-Lei n 9 869, de 1969.
} 
estudo sobre as produções realizadas entre os anos de 1993 e 2012. 43 trabalhos foram identificados, sendo 41 dissertações e duas teses, que contemplaram seis grandes temas relacionados ao ensino de sociologia, nessa ordem de temas mais pesquisados: currículo; práticas pedagógicas e metodologias de ensino; concepções sobre a sociologia escolar; institucionalização das ciências sociais; trabalho docente; e formação do professor. Evidenciaram que nos anos 2000, em função da obrigatoriedade da disciplina nas escolas, o número de pesquisas sobre o ensino de sociologia ampliou.

Outro debate importante apresentado pelas autoras se refere à tendência de pesquisas sobre ensino de sociologia serem mais realizadas nos cursos de pós-graduação das faculdades de educação. Segundo elas, essa tendência evidencia um menosprezo dos cientistas sociais com as questões educacionais, pois não consideram as questões educacionais como objetos passíveis de serem estudados, relegando-as aos cursos ligados à faculdade de educação. Essa evidência explica, em parte, a dificuldade de se associar em diversos momentos os estudos e o campo de pesquisa das ciências sociais com a educação básica.

Recentemente, a permanência da sociologia no espaço escolar é colocada mais uma vez em questionamento. A Reforma do Ensino Médio de 2017 e a nova Base Nacional Comum Curricular - BNCC se apresentam como empecilhos para a estabilidade da sociologia. A partir de uma medida provisória, o governo impôs uma alteração radical da estrutura curricular do ensino médio e apesar de manter a obrigatoriedade dos conteúdos de sociologia, sua presença ainda é ambígua, pois aponta que ela deve ser inserida sob forma de estudos e práticas. A falta de clareza quanto à presença da disciplina sociologia no ensino médio na reforma também se manifesta na nova BNCC. A nova base curricular não especifica os componentes curriculares que devem ser obrigatórios, deixando a interpretação e adequação a cargo dos sistemas de ensino, uma forma arbitrária que dá ampla liberdade para organização de 40\% do currículo do Ensino Médio, correspondentes aos itinerários formativos. Isso prioriza a permanência das disciplinas tradicionais no currículo, principalmente em escolas públicas, que não terão condições de ofertar os itinerários propostos pela reforma. 
Diante dessa intermitência e considerando as complexas relações entre uma disciplina e uma ciência conservadora ou contestadora que professores de sociologia são mobilizados para pensar e desenvolver as aulas. Visa então auxiliar o indivíduo a ter autoconsciência da realidade social, de forma profunda, desnaturalizar conceitos e preconceitos reproduzidos cotidianamente, criar a ponte para uma reflexão sobre sua vida, sobre o por que, o como, o para que, para quem a sociedade funciona. Tentar compreender essas questões e pensar como a sociologia pode se fortalecer enquanto disciplina e ainda contribuir para o enfrentamento dos problemas da educação no nosso país é fundamental. Bem como refletir sobre o papel da sociologia no enfrentamento ao racismo.

\section{PRÁtICAS DOCENTES QUE ESTÃO CONTRIBUINDO PARA O ENFRENTAMENTO AO RACISMO}

Para análise dos dados da pesquisa, utilizamos o método de organização e interpretação configurado como Análise de Conteúdo. Esse método é utilizado para organizar, descrever, categorizar e interpretar documentos e textos, que propõe compreender os dados, sejam os significados explícitos ou implícitos, à luz dos objetivos da pesquisa. Segundo Moraes, a "análise de conteúdo é uma interpretação pessoal por parte do pesquisador com relação à percepção que tem dos dados. Não é possível uma leitura neutra. Toda leitura se constitui numa interpretação" (MORAES, 1999, p. 3).

Traremos para análise as falas dos entrevistados que nos auxiliarão a compreender como aulas de sociologia no ensino médio têm contribuído para o desenvolvimento de uma educação das relações étnico-raciais, de modo a analisar essas práticas pedagógicas quanto à abordagem da temática racial, e o papel do professor de sociologia na problematização das questões raciais na sociedade brasileira. Com isso buscamos identificar nas entrevistas as seguintes categorias, que entendemos serem as que irão fornecer os dados necessários para o alcance dos objetivos desse artigo. São elas:

1-Percepção do racismo na sociedade, na escola e na vida dos alunos. 
2-Práticas que abordam a temática racial e que contribuem para o desenvolvimento de uma educação das relações étnico-raciais tendo por critério de avaliação a Lei 10.639/03 e suas diretrizes.

3-Significado do ensino de sociologia para uma educação das relações étnicoraciais. (Nesse artigo será categoria 3, referente a categoria 4 da dissertação.)

Para assegurar a confidencialidade dos entrevistados, de acordo com as considerações da ética da pesquisa, resolvemos identificá-los atribuindo-lhes nomes sem quaisquer referências aos nomes reais. Esse processo geralmente é aleatório, entretanto optamos por fazer algumas homenagens nas escolhas dos nomes. Nomeamos os sujeitos com referência a personalidades negras de nosso país, que contribuíram para a luta e resistência do povo negro. Os nomes que escolhemos foram: Angenor de Oliveira (Cartola), Carolina Maria de Jesus, Francisco José do Nascimento, Lélia Gonzales, Luiz Gama, Marielle Francisco da Silva e Milton Santos.

\subsection{PERCEPÇÃO DOS DOCENTES A RESPEITO DO RACISMO NA SOCIEDADE, NA ESCOLA E NA VIDA DOS SEUS ALUNOS}

Antes de planejar suas aulas sobre a temática étnico-racial, é recomendável que os professores tenham a compreensão sobre quais condições as relações raciais foram estruturadas em nosso país, bem como suas consequências na dinâmica social. Ficou evidente nas respostas dos professores e professoras que todos percebem o racismo como um problema social presente na sociedade brasileira e apontaram como percebem as consequências desse problema para a sociedade, para a escola e para a vida dos jovens. A sociedade brasileira é racista e reproduz diversas discriminações raciais cotidianamente, que, infelizmente, são reproduzidas na escola, ocasionando uma vida cheia de turbulências e violências para os jovens, como apontam Gomes e Laborne,

O racismo não é uma mera consequência da violência que assola a juventude negra brasileira. Ele também não é um epifenômeno da questão de classe ou somente uma questão do Estado. $\mathrm{O}$ racismo é violento e produz violência. Uma violência 
que incide sobre determinados sujeitos, portadores de sinais diacríticos específicos, frutos de uma ancestralidade negra e africana. No imaginário sociorracial, aos portadores desses sinais soma-se tudo de negativo que a violência racista construiu no contexto das relações de poder, na luta de classes, na desigualdade de gênero e sexual (GOMES e LABORNE, 2018, p. 215).

Para o professor Francisco o racismo é estrutural, faz parte das estruturas da sociedade brasileira, está enraizado nas instituições e é negado pela população, que acredita no mito da democracia racial, ainda hoje, conforme sua fala a seguir,

\begin{abstract}
Bom, eu vejo o racismo no Brasil como algo estrutural, muito estrutural, tão estrutural que as pessoas não se dão conta de como que ele funciona... A questão de raça aqui no Brasil eu acho extremamente complicada porque ela é negada, é como se ela não existisse, o mito da democracia racial ainda é muito forte e parece que as pessoas estão muito mais empenhadas em, isso eu falo dentro da escola, em resolver uma situação de racismo em especifico "olha, tal pessoa chamou o outro de macaco" do que efetivamente encarar esse racismo como algo estrutural. Então eu acho que o racismo no Brasil é muito dissimulado, e até evita o enfrentamento que a gente precisa ter. (ENTREVISTA FRANCISCO, 2019)
\end{abstract}

Esse ponto de vista é compartilhado pelo professor Milton, que reforça a dificuldade que a nossa sociedade tem em debater o racismo, pois se acredita na democracia racial.

Infelizmente, como já discutíamos anteriormente, o racismo é reproduzido dentro das instituições escolares de diversas maneiras, seja no currículo, nas práticas dos professores, entre os próprios alunos, na falta de representatividade na equipe pedagógica, dentre outras. Reconhecer essa reprodução é um primeiro passo para enfrentar esse quadro. Evidenciando os racismos dentro das escolas, reconhecendo que eles existem, é possível criar práticas antirracistas. Para Gonçalves (2006) a escola contribui para a manutenção de preconceito racial que se configura em exclusão social, ocupacional e educacional.

Perguntamos aos professores entrevistados como eles percebem o racismo dentro das escolas em que trabalham e as repostas foram contundentes e reafirmam a questão apresentada acima. Francisco e Angenor acreditam que a própria falta de representação de professores negros já é resultante do racismo estrutural 
Lélia nos diz que percebe o racismo na classificação que os professores fazem dos alunos, sendo que os considerados difíceis e problemáticos são sempre os negros. Ela ainda aponta duas formas de atuação do racismo dentro da escola, sobre um racismo colado na estética, dos jovens se verem enquanto pessoas bonitas, desejáveis, quando os jovens reproduzem os comentários "eu sou preta, mas eu sou limpinha" e uma sexualização das meninas negras muito grande. Além da questão religiosa, onde relata que um aluno, durante sua aula, falou que era primeira vez que se sentia à vontade pra falar que era de uma religião de matriz africana, porque sempre é chamado de macumbeiro.

Milton amplia a discussão,

Eu vejo falas, eu me lembro de uma fala muito curiosa da diretora quando a gente estava falando da semana de consciência negra. Eu perguntei como que era a semana da consciência negra, o que eles fazem e tals. E ela é branca e falou assim "eu não sei pra que que existe isso, semana passada eu tava no meu carro e um cara me fechou e me chamou de loira burra e o cara era negro, e porque que eu não posso xingar ele também.”. Ai eu expliquei a ela que não é a mesma coisa; a questão da gente trazer a consciência negra pra escola é justamente pra gente entender, pra desmistificar essas questões. E ela ficou assim, meio aérea. Mas eu vejo, triste demais. (ENTREVISTA MILTON, 2019)

$\mathrm{O}$ racismo age de formas perversas na vida desses jovens, seja no cotidiano das escolas, vivenciando todas essas formas que os professores relataram, seja em outros espaços da sociedade. O professor Francisco e o professor Luiz apontam que pela sociologia ter apenas um horário na semana, o convívio com os jovens é pouco, o que impede de perceber de forma mais profunda como que o racismo atua na vida de seus alunos.

Os outros professores e as professoras disseram que por diversas vezes conseguiram ter essa percepção, como também informaram que por vezes são interpelados por seus alunos com algum relato relacionado a esse assunto. Tanto Marielle, Milton, Lélia e Angenor, disseram que seus alunos relatam e reclamam, invariavelmente, de situações de como são perseguidos pelos seguranças das lojas e dos "pulões" da polícia. Os professores também apontam que percebem que seus alunos muitas vezes não têm consciência de que diversas violências que eles sofrem é racismo, mais uma consequência 
da falta de debate dentro das escolas. Como também identificam que eles têm vergonha de relatar certas situações, que remetem a questões que eles não se sentem confortáveis para falar.

Diante das formas de opressão, preconceito e discriminações que os jovens vivem, é importante identificar que eles resistem. Assim como toda a população negra vem resistindo a todas as formas de racismo, os alunos também criam suas estratégias para sobreviverem dentro e fora das escolas. Duas professoras reforçam em seus relatos a presença dessa resistência entre suas alunas. Marielle diz que tem um movimento negro em sua escola, principalmente de mulheres, muito engajadas. E Lélia aponta que também percebe essa onda do movimento das cacheadas, que elas estão ressignificando muita coisa.

O professor Angenor ainda reforça que não tem como as pessoas não enxergarem o racismo na sociedade. Para ele é uma escolha enxergar e não enxergar. As falas das professoras e professores corroboram a literatura que afirma a existência do racismo na sociedade, bem como evidenciam como a escola reproduz diversas formas de discriminações e violências, como Gomes e Laborne apontam.

\subsection{PRÁTICAS QUE ABORDAM A TEMÁTICA RACIAL E QUE CONTRIBUEM PARA O DESENVOLVIMENTO DE UMA EDUCAÇÃO DAS RELAÇÕES ÉTNICO-RACIAIS TENDO POR CRITÉRIO DE AVALIAÇÃO A LEI 10.639/o3 E SUAS DIRETRIZES}

Essa pesquisa tem como objetivo principal compreender como as práticas pedagógicas de professores de sociologia têm contribuído para o desenvolvimento de uma educação das relações étnico-raciais. Portanto, o foco é entender como suas práticas abordam a temática no sentido de implementar as orientações da Lei 10639/03, como têm enfrentado o racismo, como têm debatido o tema sob a perspectiva do ensino de sociologia. Entendemos que não existe uma receita de bolo, um formato único a ser seguido, uma proposta pronta e acabada de como se deve dar aula sobre questões raciais 
e racismo. Entretanto, analisar alguns exemplos de aulas que já estão sendo desenvolvidas nos fortalecerá nesse caminho de construção de uma educação antirracista. Para refletirmos se essas práticas estão de fato sendo antirracistas utilizamos como critério de avaliação a Lei 10639/o3 e suas diretrizes.

De acordo com Nilma Lino Gomes (2012), as práticas pedagógicas na perspectiva da Lei 10.639/03, são práticas que dependem das condições materiais e afetivas para sua implementação; em que todos os envolvidos precisam ser valorizados, bem como a cultura e história do povo negro do Brasil e da África; que questionam os preconceitos e estereótipos estabelecidos; que reconhecem a luta dos negros escravizados e a contribuição deles para nossa história; que não naturalizam as "brincadeiras e piadas" que inferiorizam as características físicas do povo negro e sua cultura; que fortalecem a criação de uma identidade negra positiva para incentivar os jovens; que são realizadas no cotidiano escolar, em conjunto com toda a comunidade escolar e com parceiros de toda a sociedade; desconstroem os equívocos em relação a tentativas de tornar o negro responsável pelo racismo e o mito da democracia racial; devem dialogar com todos, brancos e negros; devem estar inseridas nos Projetos Político-Pedagógicos (PPP) das escolas; e buscam conteúdos em diversas fontes, como nos Núcleos de Estudos AfroBrasileiros (NEABs) e grupos correlatos; apontam críticas aos materiais didáticos que reproduzem o racismo.

O Professor Francisco desenvolve suas aulas sobre a temática apresentando dados estatísticos sobre a realidade brasileira, principalmente no que tange às desigualdades raciais que assolam a população negra. Ele utiliza dados do IBGE, mapa da violência, e outras fontes de dados atuais. Ele descreve suas estratégias:

Eu trabalho basicamente com dados, eu levo dados pra mostrar, um dado que é que a mulher negra ela tem, por exemplo, muito mais dificuldade pra ter carteira de trabalho assinada. São dados expostos. Dessa maneira fica muito difícil ver contra-argumentos vazios, ai dificilmente eles vão falar que racismo não existe ou esse tipo de coisa. Minha aula é 100\% expositiva e eu sempre peço pra eles algum tipo de trabalho por escrito e algum tipo de produção que eles façam que gera um debate. Então, por exemplo, um dos trabalhos que eu costumo utilizar sempre no $3^{0}$ ano é a produção de um podcast. Eles têm que produzir um podcast sobre os 
temas que a gente tratou. Então, obviamente que a questão de raça aparece, coisas básicas como direitos humanos que dizem que todos são iguais. Obviamente que o racismo vai aparecer, uma justiça justa para todos, que está dentro dos direitos humanos, é óbvio que a questão racial vai aparecer. Então eles têm que produzir sim, e eu nunca vi a negação do racismo, das desigualdades, mas eu também vejo uma relação muito forte que os alunos fazem que aquilo que o negro sofre o pobre também sofre. Então, a questão das cotas é que precisa ser discutida 'ah, não devia ser pra negro, tinha que ser pra pobre; a violência não afeta só os negros, afeta os pobres', esse tipo de coisa, mas fora isso.. (ENTREVISTA FRANCISCO, 2019)

\section{A professora Marielle trouxe um exemplo em que trabalha esse assunto na relação} com outras temáticas. Ela discorre sobre uma atividade que fez com seus alunos:

Mas assim, eu fiz um exercício muito legal. Um grupo de jovens do Rio de Janeiro estava indo pra praia de Ipanema e aí a polícia começou a barrar esses jovens na saída lá na comunidade. Aí eles ficaram indignados e tal, eu pedi pra eles escreverem e abri pro debate. Foi uma aula sobre violência urbana, a gente lia um texto falando sobre desigualdade espacial e como que o espaço urbano reflete essas desigualdades sociais, onde certas pessoas podem frequentar e outras não, e o exercício era uma notícia e fazer essa análise e foi bem interessante. Além disso, organizei com outros professores e os alunos uma exposição de cientistas negras. E tenho tentado mudar um pouco a discussão, quando eu cresci a questão racial era muito baseada no racismo, e hoje eu vejo que ela mudou, no sentido de mostrar a luta do povo negro. E relaciono aos outros temas. (ENTREVISTA MARIELLE, 2019)

\section{Milton também responde que tem trabalhado de forma interseccional, pois acredita}

que a questão racial está presente em todas as discussões. Enunciou o que está a seguir:

$\mathrm{Eu}$ tenho tentado trabalhar essas questões de uma maneira meio que interseccional. Houve situações que a abordagem teve a questão do racismo de uma forma explicita, e o recorte racial permeia tudo né, ainda mais quando vamos pensar Brasil, não tem como não falar de recorte racial e eu tento abordar da minha maneira. Então, às vezes é mais expositivo, por exemplo, teve algumas aulas que acabamos entrando em discussão sobre violência policial e eu lembro que eu usei vídeo de uma série $O$ maluco no pedaço, do Will Smith, que aborda isso e eles falam que são abordados do mesmo jeito, 'e por que que vocês acham que são abordados?', ‘Ah, porque a gente é preto né fessor' e é isso. Às vezes eu tento trazer recurso áudio visual, rap eu tento utilizar muito com eles, é uma ferramenta muito forte nesse sentido também, eles tão mais pro funk, mas eu tento, música me ajuda muito nesse sentido também. (ENTREVISTA MILTON, 2019) 
A docente Lélia desenvolve um plano de aula específico sobre a temática racial e o apresentou para nós:

Eu trago primeiro a Diáspora, e aí depois eu falo as teorias eugenistas, os métodos antropométricos, de medição de crânio, que é uma coisa que eles gostam e aí eu conto alguns casos verídicos que a ciência já fez que foi muito racista, como a ciência corroborou com essas teorias racistas. E aí eu falava como que na sociologia foi interpretado isso, falava um pouco de Gilberto Freyre, Casa Grande e Senzala, e depois eu falava das teorias que contestavam a teoria dele, com Sergio Buarque e Florestan Fernandes, e depois ir pro Stuart Hall com identidade, como que a gente formou isso e eu chego dar junto um pouco do Castells. Eu usava muito vídeo, muita música, usava muita música da minha terra, a gente tem muita música lá que ninguém conhece aqui, pra trabalhar raça. Eu trabalhava música do Quilomboclada, o próprio nome da banda já ia explicando, quilombo com caboclada, usava fotografia, então eu gosto de usar muito imagens, acho que visualmente é bom. E eu gosto de botar eles pra fazer; vamos fazer uma pesquisa sobre esse tipo de funk, eu quero que vocês tragam a pesquisa, eles aprendem muito mais, eles botando a mão na prática. (ENTREVISTA LÉLIA, 2019)

Angenor discorre sobre suas ações e aponta que além de trabalhar de forma específica também relaciona com outros debates, bem como diz da necessidade de se apresentar um debate racial de forma positiva. Ele fez os seguintes apontamentos:

Eu sempre trabalho, de uma forma que seja não diretamente a questão do racismo, mas a gente traz no nosso debate, sempre aparece, só deixar a galera falar que cê vai escutar, eles sempre trazem. E como que eu trabalho essa questão da identidade negra, até então que eu tenho feito, tem uma aula que eu montei que é pensando exatamente isso, porque que a gente tem tanta dificuldade em se assumir negro. 'A gente', as pessoas negras, e ai eu falo do Florestan Fernandes, mito da democracia racial e tal tal tal, e sempre trago também vídeos, falas, músicas, Emicida o tempo todo, Racionais o tempo todo, um vídeo que é chocante e maravilhoso é o da "Cota não é esmola", como que aquela menina, a Bia Ferreira cantando, impacta de uma forma que eu não preciso falar nada, e aí eu tô falando de cotas, ações afirmativas, porque quando eu tô falando de ações afirmativas eu tô falando de outras ações afirmativas no geral, mas de alguma forma eu também tô falando de cotas, mas ai pensando numa outra perspectiva que não necessariamente vou falar de opressão. (ENTREVISTA ANGENOR, 2019)

Nessas entrevistas, percebemos que diversas são as possibilidades de se trabalhar a temática étnico-racial nas aulas de sociologia e que cada uma delas pode contribuir para o enfrentamento ao racismo e implementação da Lei 10639/03. Mesmo que alguns 
professores não tenham conhecimento aprofundado sobre a lei, eles desenvolvem ações que permeiam as orientações e diretrizes dessa lei, como evidenciaram em suas falas. Ao dialogar sobre a realidade brasileira, que é desigual e racista, ao trazer teorias que fundamentam a existência do racismo no Brasil, ao expor situações que ocorrem no cotidiano dos jovens brasileiros, ao debater a questão da identidade negra e religiosidades de matriz africana, ao afirmar a necessidade de ações afirmativas e cotas raciais, dentre outras práticas, os professores estão contribuindo para uma educação das relações étnicoraciais. Percebemos que existem várias lacunas ainda, seja pela falta de formação, pela dificuldade em lidar com o tema, pela resistência em debater tal temática ou pela falta de experiência em lidar com assuntos conflituosos, tanto que em sua maioria as práticas trazem como conteúdo principal a denúncia ao racismo e às desigualdades raciais, mas não apresentam conhecimentos sobre a cultura e história africana, por exemplo.

\subsection{SIGNIFICADO DO ENSINO DE SOCIOLOGIA PARA UMA EDUCAÇÃO DAS RELAÇÕES ÉTNICO-RACIAIS}

Para a implementação da Lei 10639/o3 e de suas diretrizes, para uma prática pedagógica antirracista o desempenho docente precisa ser responsável e entender que a sua prática é parte do processo de desconstrução do racismo na sociedade, ou pode contribuir para a manutenção do mesmo. Dessa forma, refletir sobre o significado do ensino de sociologia e a responsabilidade dos professores nesse processo na escola é uma parte importante da estratégia da educação das relações étnico-raciais. Nas entrevistas os docentes responderam acerca dessas responsabilidades e como eles acreditam que estão contribuindo para o enfrentamento ao racismo. Oliveira (2016) considera que o ensino de Sociologia tem condições privilegiadas para o desenvolvimento de práticas pedagógicas que debatam as questões raciais, que desnaturalizam e combatam o racismo, que reflitam sobre a história e cultura afro-brasileira e africana.

O professor Francisco defende que a sociologia deve ser uma disciplina que proponha ao jovem se retirar da acomodação. Ele aponta o seguinte: 
Pra mim o papel da sociologia é incomodar, é isso que me move a dar minhas aulas. Então, eu monto as minhas aulas imaginando como irei incomodar os alunos, aquela ideia de tirar um véu que foi colocado, como se o mundo fosse assim e pronto e acabou. Então, eu acho que a sociologia tem essa função de incomodar, e ela não incomoda só os alunos, ela incomoda os outros professores... Eu nunca tive desavenças com pais e professores, mas sei que gera esse incômodo, e acho que esse incômodo é extremamente necessário. Se a sociologia não incomodar, ela tá lá pra que? (ENTREVISTA FRANCISCO, 2019)

O docente Milton avalia que nossa tarefa principal é desnaturalizar as questões. Para ele, não é natural que o corpo docente seja branco e quem sirva seja negro. Diz que é papel da sociologia debater como essas relações têm uma construção sócio histórica, que é resultado de como se deu a abolição da escravidão e outras coisas que têm que ser levadas para a sala de aula. Dessa forma, o professor acredita que vai desmitificando esses assuntos na aula e propõe reflexões sobre o cotidiano dos jovens.

A professora Lélia defende que as aulas de sociologia são uma das melhores formas de combate ao racismo, de desmitificar essa ideologia, pois é próprio da matéria. Mas enfatiza que deveria acontecer sincronizadamente com outras matérias para ter mais efeito: "por exemplo eu já trabalhei dados da violência contra a mulher com o professor de matemática usando infográficos; trazer estatísticas com dados sensibiliza muito". Ela ainda diz que a sociologia muda muito, que as ciências humanas cumprem um papel libertador e que debate na sala de aula é essencial, assim como foi pra ela "pois ele não seria feito na minha casa, não seria feito na igreja, não seria feito no meu trabalho, esse debate começou na minha escola”.

Angenor reconhece o papel do movimento negro nesse processo e faz algumas reflexões:

Eu acho que a gente tem que mexer em estratégias muito fortes, porque é um troço muito complicado, ne? Mas o que eu tenho reparado inclusive é que o movimento social tá tocando isso mais, sabe? Nessa escola que eu tô agora por exemplo todas as pessoas negras trabalham de alguma forma isso. Então eu acho que a sociologia ela, é cruel falar isso, mas nossa formação a gente não teve ninguém que sensibilizasse a gente, mas eu acho que foram as vivências. Por exemplo, o Fórum Social Mundial que eu fui por causa da sociologia me deu essa vivência com o movimento negro lá. Então, eu acho que a sociologia traz pra gente algumas ferramentas que nos ajudam. (ENTREVISTA ANGENOR, 2019) 
A professora Carolina tem um entendimento de que a sociologia promove mudanças, tem grande repercussão ao discutir racismo, pois quando um colega negro fala sobre suas experiências de racismo e um colega branco de classe média escuta, ele vai refletir sobre isso. Portanto, é fundamental discutir essa temática. Porém, enfatiza que é um problema a maioria dos professores e diretores das escolas serem brancos, pois não há representatividade negra e o jovem não se identifica. Com isso, reforça que "é crucial discutir isso, fundamental pra sociedade mudar. Se a gente levar isso pra sala de aula e eles refletirem sobre, é muito importante mesmo".

As falas dos professores corroboram com Oliveira (2016) no sentido que todos consideram que o ensino de sociologia pode e deve contribuir para uma educação das relações étnico-raciais.

\section{CONSIDERAÇÕES FINAIS}

A investigação revelou diversas possibilidades para um ensino de sociologia comprometido com uma abordagem crítica das relações étnico-raciais e possibilitou a compreensão de como essas práticas têm contribuído para o campo da educação das relações étnico-raciais. O debate a respeito das desigualdades raciais tem sido feito utilizando-se de estratégias as mais diversas como exemplos do cotidiano, apresentação de dados estatísticos do Mapa da Violência, vídeos e documentários que abordam a temática, músicas que fazem denúncias dos preconceitos vividos e anunciam resistência.

Os relatos dos docentes entrevistados revelam a necessidade de ter a sala de aula como espaço de escuta. A realização de rodas de conversa sobre as vivências dos jovens do ensino médio, que se caracterizam como espaços de escuta e fortalecimento entre os jovens, assume importância estratégica para o desenvolvimento da temática. Além disso, a mobilização dos jovens em torno da investigação sobre a participação de cientistas negros em várias áreas do conhecimento, a apresentação da literatura sociológica sobre a formação do mito da democracia racial, diálogos sobre a construção da identidade negra 
e importância do auto-reconhecimento e empoderamento dos jovens, também contribuem para o desenvolvimento da educação das relações étnico-raciais.

O planejamento de atividades que tenham representatividade negra, independentemente do tema, a realização de debates e seminários sobre temáticas relacionadas à questão étnico-racial, como cotas raciais e ações afirmativas, são todos exemplos que elucidam como os docentes têm sido criativos para desenvolver o tema nas aulas de sociologia. Seja com um planejamento especifico ou de forma transversal, os dados apontam para práticas que, desenvolvidas da forma citada anteriormente, têm contribuído para trazer o debate étnico-racial para dentro da sala de aula, fornecendo informações e difundindo conhecimentos para educar os jovens quanto à pluralidade étnico-racial de nosso país e como a nossa sociedade tem lidado, historicamente, com as tensões das relações raciais no Brasil.

Em 2012, Gomes coordenou, em conjunto com outros pesquisadores, uma pesquisa de alcance nacional com o objetivo de mapear iniciativas que estavam implementando as Diretrizes Curriculares para Educação das Relações Étnico-Raciais. A pesquisa apontou diversas considerações, dentre elas que essas ações ainda são resultado de iniciativas individuais e isoladas de professores/as interessados/as, geralmente negros/as, em trabalhar pedagogicamente a questão racial dentro das escolas. Em consonância com a pesquisa de Gomes, a nossa investigação também evidenciou que os professores atuam principalmente de forma isolada e a partir do interesse particular do mesmo.

É incompreensível que cursos de licenciatura em ciência sociais, de universidades federais não tenham disciplinas obrigatórias sobre a história e cultura afro-brasileira e africana, nem discutam as legislações que impulsionam uma educação justa e democrática, com respeito à diversidade cultural de nossa população. Portanto, por mais que já tenham se passado 17 anos da aprovação da lei, é necessário que a luta pela implementação de suas diretrizes seja permanente e contundente. 


\section{Referências}

ANDRADE, Maíra Pires. A branquitude e a colonialidade na prática docente na educação básica (2000-2015). Revista da ABPN • v. 10, Ed. Especial - Caderno Temático: História e Cultura Africana e Afrobrasileira - lei 10.639/o3 na escola • maio de 2018, p.238-264.

BRASIL. Lei no 10.639 de 09 de janeiro de 2004. Brasília, 2003. Disponível: http://www.planalto.gov.br/ccivil_o3/leis/2003/110.639.htm>. Acesso em: 23 de set. de 2020.

. Lei no 9.394/o6, de 20 de novembro de 1996. $8^{\text {a }}$ ed., Brasília: 2003. Disponível em: < portal.mec.gov.br/seed/arquivos/pdf/tvescola/leis/lein9394.pdf>. Acesso em: 23 de set. 2020.

CAVALLEIRO, Eliane. Discriminação racial e pluralismo nas escolas públicas da cidade de São Paulo. In: Educação anti-racista: caminhos abertos pela Lei Federal $\mathrm{n}^{0}$ 10.639/03. Secretaria de educação continuada, alfabetização e diversidade - Brasília: Ministério da educação, secretaria de educação continuada, alfabetização e diversidade, 2005.

FREYRE, Gilberto. Casa Grande e Senzala. Introdução à história da sociedade patriarcal no Brasil. Rio de Janeiro: Record. 1954.

GOMES, Nilma Lino. O movimento negro educador: saberes construídos nas lutas por emancipação. Petrópolis:Vozes, 2018.

. Movimento negro e educação: ressignificando e politizando a raça. Educação e Sociedade, Campinas, v. 33, n. 120,p. 727-744, 2012.

O movimento negro no Brasil: ausências, emergências e a produção dos saberes. Política \& Sociedade, Florianópolis, v. 10, n. 18, p. 133-154, abr. 2011.

Limites e possibilidades da implementação da Lei 10.639/o3 no contexto das políticas públicas em educação. In: PAULA, M.; HERINGER, R. (Org.). Caminhos convergentes: Estado e sociedade na superação das desigualdades raciais no Brasil. Rio de Janeiro: Heinrich Böll Sti" ung; Action Aid, 2009. p. 39-74. 
GONÇALVES e SILVA, Petronilha Beatriz; BARBOSA, Lúcia Maria de Assunção (Orgs.). O Pensamento Negro em Educação no Brasil: expressões do movimento negro. São Carlos, SP: EdUFSCar, 1997.

GUIMARAES, Antônio S. A. Como trabalhar com "raça" em sociologia. Educação e Pesquisa, São Paulo, v.29, n.1, p. 93-107, jan./jun. 2003

HANDFAS, A.; MAÇAIRA, J. P. O estado da arte da produção científica sobre o ensino de sociologia na educação básica. BIB. Revista Brasileira de Informação Bibliográfica em Ciências Sociais , v. 74, p. 45-61, 2012.

MALDONADO-TORRES, Nelson. Sobre la colonialidad del ser: contribuciones al desarrollo de un concepto. In: MALDONADO-TORRES, Nelson (Org.). El giro decolonial: reflexiones para uma diversidad epistêmica más allá del capitalismo global. Bogotá: Siglo del Hombre Editores; Universidad Central, Instituto de Estudios Sociales Contemporáneos y Pontificia Universidad Javeriana, Instituto Pensar, 2007.

MORAES, Roque. Análise de conteúdo. Revista Educação, Porto Alegre, v. 22, n. 37, p. 7-32, 1999.

MOURA, Clóvis. Sociologia do negro brasileiro. São Paulo: Ed. Ática. 1986.

QUIJANO, Anibal. Colonialidade do poder, eurocentrismo e América Latina. In: LANDER, E. (Org.). A colonialidade do saber: eurocentrismo e ciências sociais perspectivas latino-americanas. Buenos Aires: Clacso, 2005. p. 227-278.

SALES JR., Ronaldo. Democracia racial: o não-dito racista. Tempo soc. [online]. 2006, vol.18, n.2, pp.229-258.

SCHWARCZ, Lilia Moritz. O espetáculo das raças: cientistas, instituições e questão racial no Brasil - 1870-1930. São Paulo: Companhia das Letras, 1993.

SOUZA, Jessé. A elite do atraso: da escravidão à Lava-Jato. Leya, Rio de Janeiro: 2017.

Sobre os autores

José Eustáquio de Brito: Graduado em Filosofia, mestre e doutor em Educação. Professor da Faculdade de Educação da Universidade do Estado de Minas Gerais (UEMG). 
Pesquisador vinculado ao Núcleo de Estudos e Pesquisas sobre Educação e Relações Étnico-Raciais da UEMG. E-mail: joseeustaquio.brito@uemg.br

Isabela Rodrigues Ligeiro: Graduada em Ciências Sociais pela UFMG. Mestra em Educação pela UEMG. Professora de Sociologia e Supervisora Escolar. E-mail: belaligeiro@gmail.com 